\title{
Rancang Bangun Alat Spot Welding Menggunakan Transformator Oven Microwave Dengan Kendali Dimmer
}

\author{
Burhanul Aziz ${ }^{1}$, Winarso ${ }^{2}$, Dian Nova Kusuma Hardani ${ }^{3}$ \\ Program Studi S1 Teknik Elektro, Universitas Muhammadiyah Purwokerto \\ Fakultas Teknik dan Sains, Universitas Muhammadiyah Purwokerto
}

\section{Informasi Makalah}

Dikirim, 19 Agustus 2020

Direvisi, 22 Desember 2020

Diterima, 29 Desember 2020

\section{Kata Kunci:}

Las Titik

Microwave Oven Transformer

Modul Dimmer

\section{Keywords:}

Spot Welding

Microwave Oven Transformer

Dimmer Module

\begin{abstract}
INTISARI
Las titik salah satu metode penyambungan menggunakan cara pengelasan resistansi listrik dimana dua atau lebih lembaran logam dijepit di antara kedua elektroda yang diberi tekanan. Hampir semua jenis logam tipis dapat dilas menggunakan las titik (spot welding). Las titik sangat dibutuhkan bagi industri rumah tangga, akan tetapi harga las yang mahal dan daya las yang besar mengakibatkan las titik kurang efisien untuk industri kecil. Oleh sebab itu, las titik dengan daya kecil dan rancang bangun yang mudah dibawa sangatlah dibutuhkan. Proses perancangan las titik dilakukan dengan tahapan yaitu perencanan, penjelasan fungsi komponen, dan pengujian daya listrik yang digunakan. Transformator yang digunakan adalah Microwave Oven Transformer (MOT) yang dirubah kumparanya dengan daya 900 Watt, dilengkapi dengan modul dimmer sebagai kendalinya. Pengujian dilakukan pada transformator untuk mengetahui nilai daya masukanya (P input) yaitu sebesar $644 \mathrm{~W}$, nilai daya keluaranya (P output) sebesar 126,94 W, dan efisiensi transformator sebesar $19,71 \%$, sedangkan nilai rugi-rugi daya berupa rugi inti sebesar $133 \mathrm{~W}$ dan rugi tembaga $123 \mathrm{~W}$. Selain itu alat las titik mampu digunakan untuk mengelas pada plat dengan ketebalan kurang dari $1 \mathrm{~mm}$. Faktor yang mempengaruhi hasil pengelasan yaitu besarnya arus, ketebalan media dan durasi saat pengelasan. Semakin besar nilai arus maka semakin besar efek dari pengelasan.
\end{abstract}

\footnotetext{
ABSTRACT

Spot welding, one of the connection methods, uses an electrical resistance welding method where two or more metal sheets are clamped between the two electrodes that are pressured. Almost all types of thin metals can be welded using spot welding. Spot Welding is needed for the home industry, but the high price of welding and considerable welding power make spot welding less efficient for small enterprises. Therefore, spot welding little energy with a simple design and easy to use is needed. The spot welding design process is carried out in stages, namely planning, explaining component functions, and electrical power. The transformer used is a Microwave Oven Transformer (MOT), which is changed by a coil with 900 Watt power, equipped with a dimmer module as a control. Tests carried out on the transformer to determine the value of the input power (Pin) that is equal to $644 \mathrm{~W}$, the value of the output power (Pout) of $126.94 \mathrm{~W}$, and the efficiency of the transformer is $19.71 \%$, while the value of power losses in the form of core losses of $133 \mathrm{~W}$ and copper losses of $123 \mathrm{~W}$. Able to be used to weld on plates with a thickness of less than $1 \mathrm{~mm}$. Factors that influence welding results are the amount of current, the width of the media, and the welding duration. The higher the current value, the greater the effect of welding.
} 


\author{
Korespondensi Penulis: \\ Burhanul Aziz \\ Program Studi Teknik Elektro \\ Fakultas Teknik dan Sains, Universitas Muhammadiyah Purwokerto \\ Jl. Raya Dukuh Waluh Purwokerto, 53182. \\ Email: $\underline{\text { aziznulburhan@gmail.com }}$
}

\title{
1. PENDAHULUAN
}

Las titik (Spot Welding) adalah salah satu metode penyambungan logam dengan pengelasan, pada permukaan plat yang disambung satu sama lain, saat yang sama arus listrik dialirkan sehingga permukaan tersebut menjadi panas dan mencair karena adanya resistansi listrik. Las titik banyak digunakan di industri besar seperti industri mobil, industri motor dan lain sebagainya. Pada umumnya digunakan untuk penyambungan logam tipis. [1]

Spot welding merupakan salah satu cara pengelasan resistansi listrik, dimana dua atau lebih lembaran logam dijepit di antara dua elektroda logam, kemudian arus yang kuat dialirkan melalui elektroda tembaga, sehingga titik di antara pelat logam di bawah elektroda yang saling bersinggungan menjadi panas akibat resistansi listrik hingga mencapai suhu pengelasan, sehingga mengakibatkan kedua pelat bagian menyatu. [2]

Salah satu parameter yang sangat berpengaruh adalah arus listrik, karena arus listrik akan mempengaruhi panas yang dihasilkan sehingga mampu untuk melelehkan logam. Las tahanan listrik (resistance spot welding) memiliki kelebihan mudah dioperasikan karena tidak dibutuhkan keahlian khusus seperti metode pengelasan lainnya, waktu lebih singkat, sehingga akan meningkatkan kecepatan produksi yang berdampak pada efisiensi waktu yang lebih baik. [3]

Perancangan alat spot welding dapat menggunakan Transformator Microwave dengan hasil out $2-3$ volt. Menggunakan struktur besi, karet dan komposit sebagai material dari alat dan menggunakan spring sebagai penarik. Jenis material yang digunakan pada elektroda alat spot welding itu merupakan jenis material tungsten. Bahan tersebut merupakan jenis logam terkeras. Pada penelitiannya dibahas mengenai pengaruh jenis elektroda yang digunakan dan pengaruh terhadap media yang akan dilas. [4]

Pada penelitian ini merancang alat Spot Welding dibuat dengan memanfaatkan transformator bekas oven microwave yaitu mengubah kumparan sisi sekundernya, dilengkapi modul dimmer sebagai kendali dan menggunakan elektroda tembaga dengan alasan kemampuan hantar arus yang bagus dan mempunyai nilai hambatan jenis yang cukup kecil. Oleh karena itu, dalam perancangan ini akan menggunakan elektroda dari bahan tembaga untuk mendapatkan hasil pengelasan yang baik. Selain itu dirancang sekecil mungkin dengan tujuan mudah dibawa, dengan biaya yang sedikit, perawatan lebih mudah dan dapat digunakan dirumah dengan daya yang cukup kecil.

\section{METODE PENELITIAN}

\subsection{Diagram alur}

Dalam melakukan penelitian ini perlu dibuat alur pelaksanaan kegiatan, agar dapat memaksimalkan waktu supaya lebih efisien dan efektif. Alur penelitian dijelaskan pada Gambar 1. 


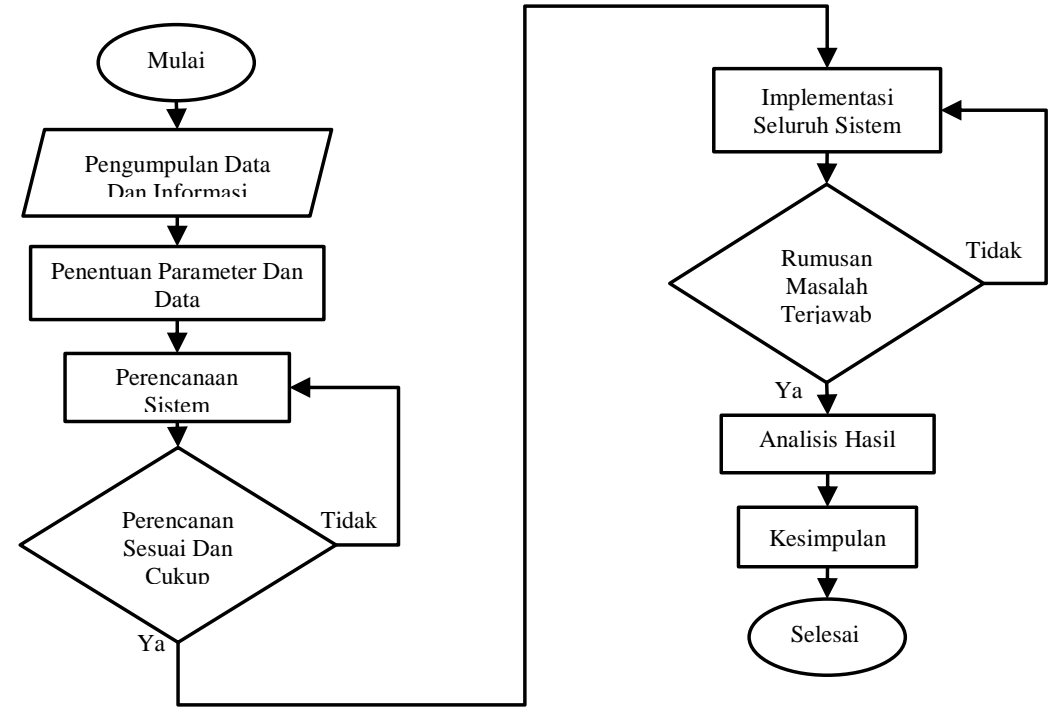

Gambar 1. Diagram alur penelitian

\subsection{Perancangan Sistem}

Alat ini terdapat dimmer modul yang berfungsi untuk mengatur besarnya nilai tegangan, dengan kata lain nilai tegangan sumber dari PLN diubah dengan nilai tertentu yang nantinya disalurkan ke trafo. Besar kecilnya nilai tersebut tergantung pada posisi dari potensio atau variable resistor. Komponen utama pada dimmer modul yaitu menggunakan TRIAC yang berfungsi sebagai saklar elektrik [5]. Alat ini juga dilengkapi dengan menggunakan voltmeter digital untuk mengetahui tegangan input pada trafo. Keluaran dari trafo disalurkan ke dua buah elekroda yang terbuat dari tembaga dengan diameter $10 \mathrm{~mm}$. Elektroda itu adalah bagian yang digunakan untuk proses pengelasan. Alat ini juga dilengkapi dengan pengaman berupa fuse dengan kemampuan 5 A dan saklar yang berfungsi untuk menghidupkan dan mematikan alat. Terdapat kipas yang digunakan untuk mendinginkan trafo dan komponen TRIAC, supaya tidak terjadi panas yang berlebih, seperti pada Gambar 2.

Pembuatan alat dilakukan dengan memanfaatkan trafo bekas oven microwave atau sering disebut MOT. Trafo MOT berfungsi untuk menaikan tegangan dari tegangan PLN menjadi ribuan volt. Kemudian kumparan sekunder trafo dirubah dengan jumlah kumparan yang lebih sedikit dan penampang yang lebih besar [6]. Perubahan kumparan sekunder dilakukan dengan tujuan untuk menurunkan tegangan pada kumparan sekunder (Vs) sampai menjadi 1-3 VAC dan untuk mendapatkan arus sekunder (Is) yang besar.

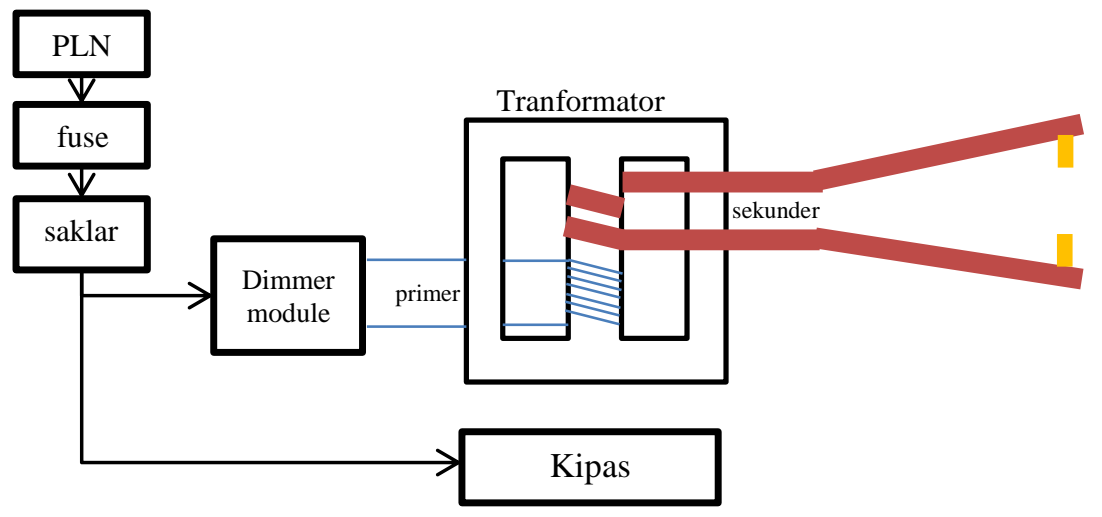

Gambar 2. Diagram blok sistem

\subsection{Pengujian Transformator}

1. Pengujian Beban Nol

Maksud pengujian ini adalah untuk menentukan rugi beban nol atau rugi inti dan untuk mencari nilai $\mathrm{X}_{0}$ dan $\mathrm{R}_{0}$. Cara pengujianya yaitu dengan cara seperti pada Gambar 3. [7] 


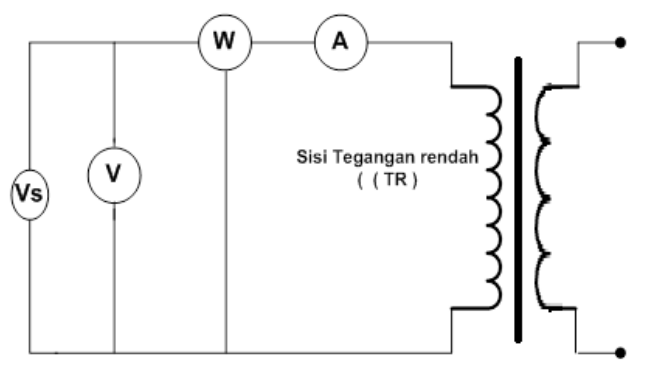

Gambar 3. Pengujian beban nol [7]

Berdasarkan nilai hasil pengujian bisa digunakan untuk mencari nilai cos $\Phi$ menggunakan persamaan (1), nilai arus magnetisasi $\left(\mathrm{I}_{\mu}\right)$ menggunakan persamaan $(2)$, nilai arus resistensi nol $\left(\mathrm{I}_{\omega}\right)$ menggunakan persamaan (3), $\mathrm{X}_{0}$ dan $\mathrm{R}_{0}$ dapat diperoleh menggunakan Persamaan (4) dan Persamaan (5).[7]

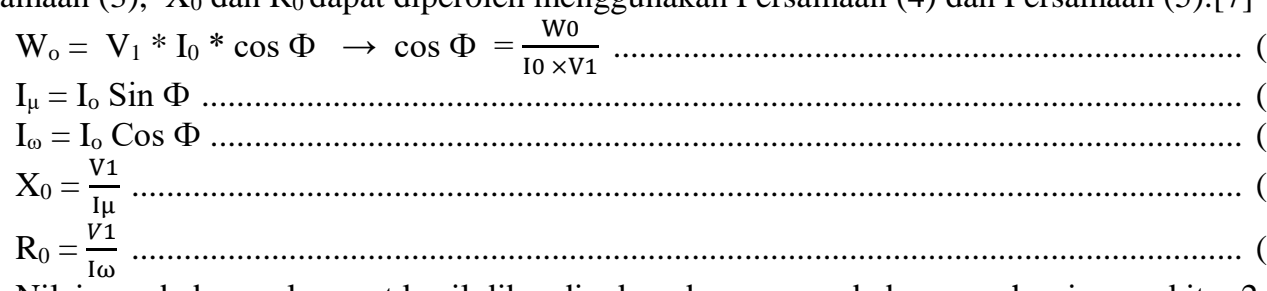

Nilai arus beban nol sangat kecil dibandingkan dengan arus beban penuh primer sekitar $2-3 \%$, oleh karena itu rugi tembaga primer dapat diabaikan. Secara praktis daya beban nol $\left(\mathrm{W}_{0}\right)$ dipergunakan untuk mengatasi rugi-rugi inti (Pi). Atau bisa juga menggunakan Persamaan 6. [7]

$\mathrm{Pi}=\mathrm{I}^{2} \times \mathrm{R}_{0}$

\section{Pengujian Beban Penuh}

Pengujian ini adalah untuk menentukan rugi-rugi pada saat beban penuh atau hubung singkat, untuk menentukan impedansi ekuivalen Ze1 dan Ze2, reaktan bocor ekuivalen Xe1 dan Xe2, resistansi total dari trafo berdasarkan kumparan dimana alat-alat ukur dipasang, jatuh tegangan total, dan untuk menentukan rugi tembaga pada saat beban penuh. Rugi tembaga digunakan untuk menghitung efisiensi trafo. Pengujian beban penuh dapat dilakukan dengan cara seperti pada Gambar 4. [7]

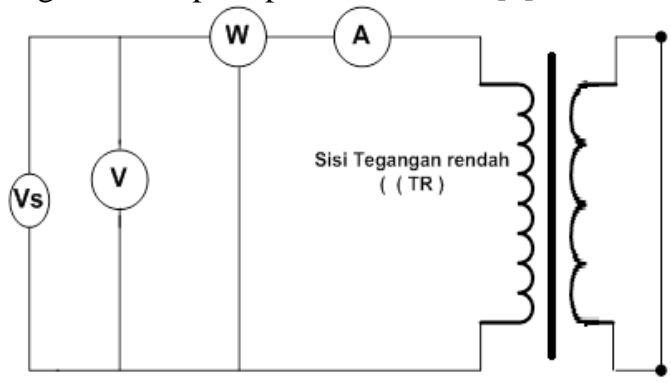

Gambar 4 Pengujian beban penuh [7]

Pengujian beban penuh mendapat beberapa parameter nilai yang nantinya digunakan untuk mencari nilai impedansi total trafo (Ze1) menggunakan persamaan (7), nilai resistansi equivalen $(\operatorname{Re} 1)$ menggunakan persamaan (8) dan nilai reaktansi equivalen (Xe1) menggunakan persamaan (9). [7]

$$
\begin{aligned}
& \mathrm{Ze} 1=\frac{\mathrm{Vsc}}{\mathrm{Isc}} \\
& \text { Psc }=\mathrm{I}_{\mathrm{sc}^{2}}{ }^{2} \operatorname{Re} 1 \text { maka } \operatorname{Re} 1=\frac{P s c}{\mathrm{Isc}^{2}}
\end{aligned}
$$

Pemberian tegangan pada sisi tegangan tinggi berkisar antara 5\% sampai 10\% dari tegangan nominal, sehingga fluks yang ada pada inti juga sekitar 5\% sampai $10 \%$ dari fluks nominalnya. Besarnya nilai fluks kecil, rugi inti sangat kecil dan yang terbaca pada wattmeter (Psc) adalah rugi tembaga (Pcu), atau untuk nilai rugi tembaga keseluruhan dapat dicari dengan Persamaan 10. [7]

$\mathrm{Pcu}=\mathrm{I}^{2} \times \operatorname{Re}$ 


\section{HASIL DAN PEMBAHASAN}

Pembuatan alat dilakukan dengan memanfaatkan trafo bekas oven microwave atau sering disebut MOT, kemudian kumparan sekunder trafo dirubah dengan jumlah kumparan yang lebih sedikit dan penampang yang lebih besar. Tegangan output atau tegangan pada kumparan sekunder (Vs) yang akan dipakai, yaitu sebesar 2 VAC. Pada perancangan kali ini menggunakan jumlah belitan yaitu sebanyak 2 lilit. Perubahan jumlah kumparan trafo ini menggunakan kabel NYAF dengan besar penampang yang digunakan sebesar 35 $\mathrm{mm}^{2}$ dengan kemampuan hantar arus sebesar 135 A (arus terus menerus). Nilai KHA dari kabel ini lebih kecil karena mempertimbangkan ukuran trafo yang digunakan termasuk kecil, dan arus yang mengalir tidak terus menerus melainkan hanya beberapa detik saja.

Dimmer module yang digunakan pada alat ini berfungsi untuk merubah nilai tegangan sisi primer. Tabel 1 menunjukan bahwa setiap perubahan posisi variable resistor mempunyai kenaikan nilai tegangan berkisar antara 25-30 V.

Tabel 1 Hasil pengukuran tegangan tiap perubahan potensio

\begin{tabular}{ccc}
\hline No & Posisi Potensio & Tegangan $(\mathrm{V})$ \\
\hline 1 & 1 & 55,1 \\
2 & 2 & 71,9 \\
3 & 3 & 112,5 \\
4 & 4 & 140,3 \\
5 & 5 & 171,3 \\
6 & 6 & 196,4 \\
7 & 7 & 223,2 \\
\hline
\end{tabular}

\subsection{Pengujian Beban Nol Atau Hubung Buka}

Hasil dari pengujian dengan kondisi tanpa beban atau beban nol didapat nilai tegangan primer (Vp) 219,6 V nilai arus primer (Ip) 1,75 A dengan daya (Po) yang terukur sebesar 58 Watt. Nilai tersebut dapat di olah untuk mencari nilai cos $\phi$ dengan menggunakan Persamaan (1).

$$
\begin{aligned}
& \cos \phi=\frac{\mathrm{Wo}}{\mathrm{Vp} \times \mathrm{Ip}}=\frac{69}{227,8 \times 2,2}=0,13 \\
& \text { maka nilai } \phi=\cos ^{-1} 0,13=82^{\circ} \\
& \sin \phi=\sin 82^{\circ}=0,99
\end{aligned}
$$

Nilai tersebut dapat digunakan untuk menghitung nilai arus $I_{\omega}$ dan $I_{\mu}$ menggunakan Persamaan (3) dan Persamaan (2).

$$
\begin{aligned}
& I_{\omega}=I_{o} \operatorname{Cos} \phi=2,2 \times 0,13=0,286 A \\
& I_{\mu}=I_{o} \operatorname{Sin} \phi=2,2 \times 0,99=2,178 A
\end{aligned}
$$

Nilai $I_{\omega}$ dan $I_{\mu}$ digunakan untuk mencari nilai $X_{0}$ dan $R_{0}$ menggunakan Persamaan (4) dan Persamaan (5).

$$
\begin{aligned}
& \mathrm{X}_{0}=\frac{V_{1}}{I_{\mu}}=\frac{227,8}{2,178}=104,6 \Omega \\
& \mathrm{R}_{0}=\frac{V_{1}}{I_{\omega}}=\frac{227,8}{0,286}=796,5 \Omega
\end{aligned}
$$

Nilai Io merupakan arus simulasi dari beban nol yang disebabkan oleh induktansi murni (arus magnetisasi $\left.=I_{\mu}\right) X_{0}$ dan resistansi nol (arus $\left.=I_{\omega}\right) R_{0}$. Arus beban nol sangat kecil dibandingkan dengan arus beban penuh sisi primer, hanya sekitar $2-3 \%$, oleh karena itu rugi tembaga primer dapat diabaikan, sehingga secara praktis daya beban nol $\left(\mathrm{P}_{0}\right)$ dipergunakan untuk mengatasi rugi-rugi inti.

\subsection{Pengujian Beban Penuh Atau Hubung Singkat}

Pengujian hubung singkat dilakukan dengan memberi nilai tegangan sumber yang bervariasi, dengan tujuan untuk melihat pengaruh besarnya tegangan terhadap nilai Ze, Re dan Xe. Pemberian nilai dari tegangan sumber (Vsc) tidak boleh terlalu besar atau mendekati nilai tegangan nominal, tujuannya supaya suhu dari trafo tidak naik terlalu drastis atau lebih parahnya lagi bisa menyebabkan email pada kumparan bisa terbakar dan 
dapat menimbulkan hubung singkat pada kumparan. Pemberian nilai tegangan sumber yang kecil, menyebabkan nilai rugi inti sangat kecil dan yang terbaca pada wattmeter (Psc) bisa di sebut rugi tembaga.

Tabel 2 Hasil Pengukuran saat pengujian hubung singkat

\begin{tabular}{lcccccc}
\hline No & Vsc $(\mathrm{V})$ & Isc $(\mathrm{A})$ & $\operatorname{Psc}(\mathrm{W})$ & $\mathrm{Ze}(\Omega)$ & $\operatorname{Re}(\Omega)$ & $\mathrm{Xe}(\Omega)$ \\
\hline 1 & 89,1 & 0,54 & 36 & 165,00 & 123,46 & 109,47 \\
2 & 73,8 & 0,46 & 26 & 160,43 & 122,87 & 103,16 \\
3 & 59,5 & 0,33 & 15 & 180,30 & 137,74 & 116,35 \\
4 & 44,6 & 0,24 & 8 & 185,83 & 138,89 & 123,47 \\
5 & 19,7 & 0,14 & 2 & 140,71 & 102,04 & 96,89 \\
\hline
\end{tabular}

Menentukan nilai impedansi ekuivalen (Ze1) dan reaktan bocor ekuivalen (Xe1) dengan cara mengetahui nilai arus hubung singkat (Isc), tegangan hubungsingkat (Vsc) dan daya hubung singkat (Psc) seperti pada Tabel 2. Sebagai sampel untuk melakukan perhitungan menggunakan hasil pengukuran pada Tabel 2 nomer 5, karena nilai teganganya $\pm 5 \%$ - 10\% dari nilai nominalnya. Nilai Ze dapat diketahui menggunakan Persamaan (7) sedangkan nilai Re1 yaitu menggunakan Persamaan (8).

$$
\begin{aligned}
& \mathrm{Ze} 1=\frac{V s c}{\mathrm{Isc}}=\frac{19,7}{0,14}=140,71 \Omega \\
& \operatorname{Re} 1=\frac{P s c}{I s c^{2}}=\frac{2}{0,14^{2}}=\frac{58}{0,09}=102,04 \Omega
\end{aligned}
$$

Nilai Xe1 diperoleh menggunakan Persamaan (9).

$$
\mathrm{Xe} 1=\sqrt{Z e 1^{2}-\operatorname{Re} 1^{2}}=\sqrt{140,71^{2}-102,04^{2}}=96,89 \Omega
$$

Nilai Xe, Re dan Ze sudah diketahui sehingga bisa dicari nilai arus (I) dan rugi tembaga (Pcu). Nilai arus (I) dapat diperoleh menggunakan persamaan hokum ohm, sedangkan mencari nilai rugi tembaga total(Pcu) menggunakan Persamaan (10).

$$
\begin{aligned}
& \mathrm{I}=\frac{\mathrm{V} 1}{\mathrm{Ze}}=\frac{220}{140,71}=1,56 \mathrm{~A} \\
& \mathrm{Pcu}=\mathrm{I}^{2} \times \operatorname{Re}=1,56^{2} \times 102,04=118,42 \mathrm{~W}
\end{aligned}
$$

Besarnya nilai rugi inti trafo (Pi) dapat diperoleh menggunakan Persamaan (6).

$$
\mathrm{Pi}=\mathrm{I}^{2} \times \mathrm{Ro}=1,56^{2} \times 796,5=198,46 \mathrm{~W}
$$

\subsection{Pengujian Pengaruh Perubahan Tegangan}

Pengujian ini bertujuan untuk mengetahui pengaruh dari nilai tegangan input pada trafo terhadap nilai arus dan daya pada sisi primer, selain itu juga terhadap nilai tegangan dan arus pada sisi sekunder trafo.

Tabel 3 Hasil pengukuran pengaruh perubahan tegangan terhadap nilai output

\begin{tabular}{cccccccc}
\hline No & Vp (V) & Ip (A) & Pin (W) & Vs (V) & Is (A) & Pout (W) & Efisiensi (\%) \\
\hline 1 & 68,8 & 1,07 & 81 & 0,38 & 44,8 & 18,73 & $23,13 \%$ \\
2 & 86,1 & 1,1 & 131 & 0,459 & 66,1 & 41,97 & $32,03 \%$ \\
3 & 105,8 & 0,78 & 111 & 0,761 & 45,1 & 46,16 & $41,59 \%$ \\
4 & 132 & 1,98 & 333 & 0,58 & 132 & 97,55 & $29,29 \%$ \\
5 & 163,2 & 2,65 & 482 & 0,64 & 173,9 & 124,04 & $25,73 \%$ \\
6 & 198,5 & 3,43 & 642 & 0,65 & 211,6 & 129,69 & $20,20 \%$ \\
7 & 219,8 & 4,04 & 644 & 0,94 & 186,2 & 126,94 & $19,71 \%$ \\
\hline
\end{tabular}


Tabel 3 merupakan nilai yang didapat dari pengukuran yaitu nilai tegangan primer (Vp), arus primer (Ip) dan daya pada sisi primer (Pin), sedangkan pada sisi sekunder diperoleh nilai tegangan (Vs) dan arus (Is). Dari data tersebut kita bisa mencari besarnya nilai $\cos \phi$ dengan menggunakan rumus daya. Pengujian ini diambil satu contoh yaitu dari Tabel 3 nomer 7, sehingga bisa ditentukan besarnya nilai cos $\phi$.

$$
\cos \phi=\frac{644}{219,8 \times 4,04}=0,73
$$

Sehingga kita bisa mencari nilai daya keluaran (Pout) trafo.

$$
\text { Pout }=\text { Vs } \times \text { Is } \times \cos \phi=0,94 \times 186,2 \times 0,73=162,94 \mathrm{~W}
$$

Besarnya nilai daya keluaran sudah diketahui yaitu sebesar 162,94 W dan daya input sebesar $644 \mathrm{~W}$, sehingga dapat dihitung efisiensi dari trafo.

$$
\text { Efisiensi }=\frac{\text { Pout }}{\text { Pin }} \times 100 \%=\frac{162,94}{644} \times 100 \%=19,71 \%
$$

Jadi nilai efisiensi trafo berdasarkan data pada Tabel 3 nomer 7 adalah sebesar 19,71\%. Nilai efisiensi yang kecil ini terjadi karena pada trafo terjadi rugi-rugi atau losses, yaitu rugi inti dan rugi tembaga. Besarnya rugi tembaga total (Pcu primer + Pcu sekunder) pada trafo adalah 118,42 W, sedangkan nilai rugi inti (Pi) dapat diperoleh 198,46 W. Selain itu juga disebabkan nilai daya keluaran yang terlalu kecil karena tegangan pada keluaran trafo (tegangan sekunder) mengalami drop tegangan dari $2 \mathrm{~V}$ menjadi 0,94 V. Drop tegangan ini terjadi karena kumparan yang di pakai pada sisi sekunder merupakan kabel NYAF yang dibungkus isolator terbuat dari bahan PVC, sehingga proses induksi medan magnet pada sisi sekunder tidak maksimal karena terhalang oleh isolator.

\subsection{Pengaruh Waktu Terhadap Hasil Pengelasan}

Pengukuran ini bertujuan untuk mengamati pengaruh lamanya pengelasan terhadap nilai tegangan dan arus pada sisi primer maupun pada sisi sekunder dan diperoleh data seperti pada Tabel 4.

Tabel 4 Hasil pengukuran pengaruh perubahan waktu dengan potensio pada posisi 7

\begin{tabular}{cccccccc}
\hline No & Waktu & Vp (V) & Ip (A) & Pin (W) & Vs (V) & Is (A) & Pout (W) \\
\hline 1 & 5 & 219,1 & 4,61 & 777 & 0,67 & 243,7 & 125,61 \\
2 & 10 & 220 & 3,87 & 672 & 0,92 & 191,9 & 139,35 \\
3 & 15 & 219,8 & 4,04 & 644 & 0,94 & 186,2 & 126,94 \\
\hline
\end{tabular}

Berdasarkan hasil pengukuran pengaruh waktu terhadap trafo pada Tabel 4, terlihat bahwa semakin lama waktu pengelasan semakin naik teganganya, walaupun kenaikan tegangan tersebut kecil dan masih cenderung tidak stabil. Kemudian nilai arus pada sisi primer semakin turun. Hal ini disebabkan karena sifat dari metal jika bersuhu tinggi maka akan menaikan nilai tahanan jenis dari media tersebut, sehingga nilai tahanan jenisnya naik dan nilai arus turun. Kemudian nilai tegangan turun karena naiknya nilai arus sesuai dengan hukum ohm.

Tabel 5 Hasil pengelasan dan kenaikan suhu setiap perubahan waktu

\begin{tabular}{ccccc}
\hline No & Waktu (detik) & Temperatur $\left({ }^{\circ} \mathrm{C}\right)$ & Arus (A) & Hasil Pengelasan \\
\hline 1 & 5 & 93,6 & 433 & \\
2 & 10 & 119,8 & 417 & \\
3 & 15 & 140,0 & 411 & \\
\hline
\end{tabular}


Pengujian dilakukan dengan kondisi potensio pada posisi 7 tegangan terukur berkisar 215,8 V, ketebalan media 0,96 mm dan durasi pengelasan yang bervariasi dari 5 detik, 10 detik dan 15 detik. Hasil pengukuran menunjukan bahwa semakin lama durasi pengelasan maka semakin tinggi temperatur media yang dilas dan semakin lebar efek dari pengelasan. Selain itu semakin besar suhu maka nilai arus semakin kecil, meskipun penurunan nilai arus tidak terlalu besar seperti pada Tabel 5. Salah satu penyebabnya adalah karna sifat dari logam apabila nilai suhu naik maka nilai resistansi ikut naik, sehingga nilai arus menjadi turun. Dapat di buktikan menggunakan persamaan hukum ohm sebagai berikut:

1. Saat nilai suhu $93,6^{\circ} \mathrm{C}$, nilai tegangan $215,8 \mathrm{~V}$ dan nilai arus $433 \mathrm{~A}$, sehinnga nilai resistansinya:

$$
\mathrm{R}=\frac{\mathrm{V}}{\mathrm{I}}=\frac{215,8}{433}=0,498 \Omega
$$

2. Saat nilai suhu $119,8^{\circ} \mathrm{C}$, nilai tegangan $215,8 \mathrm{~V}$ dan nilai arus $417 \mathrm{~A}$, sehinnga nilai resistansinya:

$$
\mathrm{R}=\frac{\mathrm{V}}{\mathrm{I}}=\frac{215,8}{417}=0,518 \Omega
$$

3. Saat nilai suhu $140,0^{\circ} \mathrm{C}$, nilai tegangan $215,8 \mathrm{~V}$ dan nilai arus $411 \mathrm{~A}$, sehinnga nilai resistansinya:

$$
\mathrm{R}=\frac{\mathrm{V}}{\mathrm{I}}=\frac{215,8}{411}=0,525 \Omega
$$

Jadi semakin tinggi nilai suhu pada media yang dilas maka nilai resistansi media tersebut bertambah besar dan berimbas kepada nilai arus yang turun, meskipun perubahanya tidak terlalu signifikan.

\subsection{Pengaruh Ketebalan Media}

Ketebalan media juga berpengaruh terhadap proses pengelasan. Pada pengujian ini menggunakan media dengan ketebalan $0,16 \mathrm{~mm}$. Pengujian dilakukan dengan variasi ketebalan dengan cara menumpuk media tersebut dari 1 lapis $(0,16 \mathrm{~mm}), 2$ lapis $(0,32 \mathrm{~mm}), 4$ lapis $(0,62 \mathrm{~mm})$ dan 6 lapis $(0,96 \mathrm{~mm})$.

Tabel 6 Hasil pengelasan dengan ketebalan media yang berbeda

\begin{tabular}{ccc|c|}
\hline No & Tebal (lapis) & \multicolumn{2}{c}{ Hasil Pengelasan } \\
\hline 1 & 1 & & \\
\hline & 2 & \\
3 & 4 & \\
\hline
\end{tabular}

Pengujian dilakukan menggunakan tegangan yang sama, durasi pengelasan yang sama, namun dengan ketebalan yang berbeda maka hasilnya pun berbeda seperti pada Tabel 6. Semakin tebal medianya maka semakin kecil efek dari pengelasanya dan sebaliknya, semakin tipis medianya maka semakin besar efek dari pengelasanya. Hal ini terjadi karena semakin tipis medianya maka semakin kecil uaha untuk melelehkan media tersebut. 


\section{KESIMPULAN}

Alat las titik (Spot Welding) dibuat dengan memanfaatkan transformator bekas oven microwave yang dirubah kumparan sisi sekundernya menggunakan kabel NYAF $1 \times 35 \mathrm{~mm}^{2}$ dengan jumlah belitan sebanyak 2 lilit. Pengembangan pada alat ini menggunakan pengendali berupa dimmer modul yang fungsinya untuk merubah nilai tegangan sumber (Vin) sehingga nilai arus ikut berubah dan berpengaruh terhadap hasil pengelasan. Nilai daya masukan (Pin) yang terukur adalah $644 \mathrm{~W}$, sedangkan nilai daya keluaranya (Pout) adalah sebesar 126,94W. Maka efisiensi dari trafo tersebut sebesar 19,71\%. Selisih antara daya masukan (Pin) dan daya keluaran (Pout) trafo sebesar 80,29\%. Hal ini terjadi karena pada trafo terjadi rugi-rugi atau losses, yaitu rugi inti sebesar 198,46 W (pada pengujian hubung buka) dan rugi tembaga sebesar 118,42 W (pada pengujian hubung singkat). Faktor yg mempengaruhi pengelasan yaitu besarnya arus, ketebalan media dan durasi saat pengelasan. Semakin besar nilai arus maka semakin besar efek dari pengelasan, semakin lama dalam proses pengelasan maka semakin besar efek dari pengelasan dan semakin tebal media maka semakin besar usaha dalam proses pengelasan.

\section{DAFTAR PUSTAKA}

[1] Andrianto, Y. Fadhila, I.M. Sifa, A. \& Endrawan, T. (2019). Perancangan Mesin Rocker Arm Spot Welding. Prosiding Industrial Research Workshop National Seminar Vol. 1 No. 1, Indramayu.

[2] Permadi, H.A.A. (2017). Redesaign dan rancang bangun mekanisme spot welding elektroda tungsten dengan menggukan microwave oven transformator. tuga. Fakultas Teknik, UMMalang, Malang.

[3] Zhang, Hongyan, (2006). Resistance Welding Fundamental and Aplication. CRC press taylor and francis group.

[4] Haikal dan Triyono. (2013). Studi Literatur Pengaruh Parameter Pengelasan Terhadap Sifat Fisik dan Mekanik Pada Las Titik (Resistance Spot Welding). Jurnal Rotasi, Vol. 15, No. 2.

[5] Dickson, kho, (2016). Pengertian SCR (Silicon Controlled Rectifer) dan Prinsip Kerjanya. https://teknikelektronika.com/pengertian-scr-silicon-controlled-rectifier-prinsip-kerja-scr), (diakses tanggal 5 April 2020).

[6] Santoso, L.H. Anwar, S. Heryana, G. \& Wiyono, A. (2018). Perancangan Sensor Counter Spot Pada Mesin Stationery Spot Welding di PT. Summit Adyawinsa Indonesia. Seminar Nasional Teknik Elektro Vol. 3 Hal. 73-78, Subang.

[7] Berahim, Hamzah. (1991). Pengantar Teknik Tenaga Listrik: Teori Ringkasan dan Penyelesaian Soal. Yogyakarta: Andi Offset. 
